\title{
Motor Skill Level of Children and Adolescents Motivation in Physical Activity: A Major Concern for Public Health and Physical Education
}

\author{
Henry Joe Tucker ${ }^{1}$, Samuel Joseph Bebeley ${ }^{2}$, Michael Conteh ${ }^{3}$ \\ ${ }^{1}$ Assistant Lecturer, Department of Human Kinetics and Health Education, School of Education, Njala University, Sierra Leone \\ ${ }^{2}$ (PhD Scholar), Lecturer, Department of Human Kinetics and Health Education, School of Education, Njala University, Sierra Leone \\ ${ }^{3}$ Graduate, Department of Human Kinetics and Health Education, School of Education, Njala University, Sierra Leone
}

\begin{abstract}
Background: Physical fitness could be referred to as a structured, organized, planned and executed physical activity, exercise and education that involves circuit training, which could require use of maximum volume of oxygen (VO ${ }_{2}$ max.), intake and expenditure of kilocalories by muscles, skeletal and cardiovascular systems for fitness, health and wellness that could help prevent lifestyle related cardiovascular illnesses, mortality and morbidity. Motor skill as a subcategory of physical activity, could be referred to as public health education factor that relates to human movement patterns of muscles and skeletal systems that could require intake and expenditure of kilocalories for improved $\mathrm{VO}_{2}$ max., fitness, wellness, healthy lifestyle and decreased cardiovascular related illnesses, morbidity and mortality. This study only aimed at scoring the measured and evaluated factors under motor skill level of children and adolescents motivation in physical activity: a major concern for public health and physical education. Methods:American Association for Health, Physical Education and Recreation (AAHPER) was the survey instrument adopted, with sampled participants of $(N=122)$ selected using a process of simple random sampling method, having a response rate of (100\%).The variables were analyzed using IBM SPSSv.23 Statistics, with mean and standard deviation $(M \pm S D)$ age recorded as $(14.5 \pm 5.5)$ ranged from (9-20)years. Results: Differences in mean and standard deviation $(M \pm S D)$ of motor skill test by age group were evidenced accordingly by highest scores as follows: Bend-Knee-SitUps (15-17) years scored (2.72 \pm 0.861$)$, Shuttle-Run (09-11) years scored (3.00 $\pm \leq 0.000)$, Standing-Long-Jump (18-20) years scored

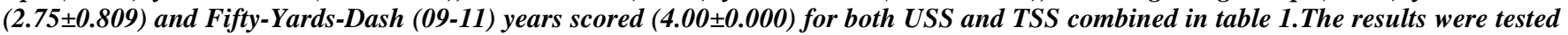
@ significance level p<0.05. Conclusion and Recommendation: It was noted that, majority of the pupils (especially boys) ranged(1520)years recorded high values during the test, displaying evidence of physical activity, exercise and motor skill development, though technicalities and names of activities were a little challenging. It was recommended that, stakeholders in the educational sector should be proactive in educating pupilsto take part in physical and health education activities for healthy lifestyle alongside decreasing obesity and cardiovascular related illnesses.
\end{abstract}

Keywords: Physical Activity, Physical Education, Public Health and Motor Skill

\section{Introduction}

Physical activity under motor skill could be referred toas a public health factor that relates to human movement patterns and structures of musculoskeletal systems that could require intake and expenditure of kilocalories for improved wellness and healthy lifestyle, which could prevent cardiovascular related diseases, morbidity and mortality, while physical fitness could be referred to as a well-structured, organized and planned physical activity and exercise programmes that involves circuit training, which could require use of maximum volume of oxygen, intake and expenditure of kilocalories by musculoskeletal and cardiovascular systems for fitness, health and wellness, which could also help prevent lifestyle related cardiovascular diseases, mortality and morbidity, Tucker et al. (2017); Bebeley et al. (2017).Physical activity also being sub category of physical education (i.e. education of and through the physical), could be referred to as an educational programme that teaches pupils and students, the physique of human kinetics, produced by musculoskeletal systems, which when undertaken regularly from moderate to vigorous physical activity (MVPA) could improve not only the physiological of individuals, but also the psychosocial health, fitness and wellness (intellectual, spiritual and social wellness) of individuals, Bebeley et al. (2017); Tucker et al. (2017).
Physical activity favoured by autonomy in selfdetermination for physical fitness, wellness and motor skill development rather than rewards and threats, could help improve greatly motivational level of school pupils and college students in physical activity, fitness and motor skill development with respect to sustainable future participation growth alongside advantages (pros.), motive, behavioural regulation, self-efficacy and weekly leisure time spent on physical activity for better physical activity status, physical fitness, wellness and motor skill development, which could be complemented by mandatory institution of programmes in physical literacy or education, fitness and wellness for all school pupils and college students before graduation, adopting and allotting enough time and attention to teaching and learning of physical literacy or education activities during and outside school or college hours, conducting seminars, training workshops and holding focus group discussions amongst pupils and students in areas of physical fitness, wellness, physical activity, exercise, motor skill development and health education as one of the fundamentals that could help greatly with sustainable future participation in physical activity, fitness, wellness and motor skill development for adolescents as well as adults, Bebeley et al. (2017); Tucker et al. (2017);Laggao et al. (2017); Bebeley (2016); Bebeley et al. (2011). 


\section{International Journal of Science and Research (IJSR) \\ ISSN (Online): 2319-7064}

Index Copernicus Value (2016): 79.57 | Impact Factor (2015): 6.391

Physical activity under the human physique could be expressed as human kinetics trajected by the musculoskeletal systems, which when undertaken regularly for a prolonged period of time (PPT) from moderate to vigorous physical activities (MVPA) devoid of injuries to the tissues of the muscles, ligaments, tendons, joints and bones, could improve physiological and psychological health and wellness and it is of significance to the holistic wellness and wellbeing of an individual, which could be more positive, productive, effective, efficient, fruitful and functional if due attention and significant recognition is giving to the teaching and learning of health and physical education or literacy in schools and colleges to improve physical activity literacy level, Bebeley et al. (2017); Tucker et al. (2017); Bebeley (2016). Physical activity could also be expressed as that aspect of public health education with determinant factors (i.e. personal, social and environmental) that deals with human kinetics of the musculoskeletal systems, which could require both energy or calorie intake and expenditure for improved and sustainable physiological and psychosocial fitness, wellness and healthy lifestyle, Bebeley et al. (2017).Physical activity under motor development could require basic aerobic endurance training for children, adolescents, youths and adults for effective approach in improvement of maximum volume of oxygen $\left(\mathbf{V O}_{2}\right.$ max.) for sustainable physical education, activity, fitness, wellness and motor skill, which could be implemented in schools (pre, primary, junior and senior high schools) and colleges especially undergraduates during physical education, fitness, wellness and literacy lessons, thereby leading to the exposure of pupils as well as students to functional movement skills and screening, designed in physical education programmes for improvement of physical fitness, wellness and motor skill level components that includes speed, agility, reaction time and power, focusing on advantages (pros.), motive, behavioural regulation, selfefficacy and weekly leisure time spent on physical activity for better physical activity status during childhood, adolescent, adulthood and old age, Bebeley et al. (2017); Tucker et al. (2017); Bebeley (2015).

In determination of individual motivation for physical activity, physical fitness, wellness and motor skill development, health professionals i.e. clinicians, public health and physical educators, could use this knowledge to create awareness and develop effective and efficient intervention that could motivate the general public especially children, adolescents and adults (young, middleaged and older adults) to frequently and constantly engage in physical activity for better physical fitness, wellness and motor skill development Bebeley et al. (2017), practice abstinence from eating disorders like anorexia nervosa, bulimia nervosa and binge eating disorders, Bebeley et al. (2017), understand about non-usage of drugs like cigarette smoking, alcohol consumption and performance enhancing drugs, Bebeley et al. (2016), practice abstinence from diseases associated with unsafe sexual practices like HIV/AIDS, syphilis and gonorrhea, Bebeley et al. (2016), focus on knowing and monitoring of vital signs like heart rate, blood pressure and body mass index, Bebeley et al. (2017), understand about preventing sport or exercise related injuries like a chilles tendinitis, runner's knee/patellofemoral pain syndrome and shin splints, Bebeley et al. (2016), understand about health literacy level of asthma due environmental, physical and medical conditions Bebeley (2016), understand about health literacy level of muscle atrophy due physical, medical and exercise factors Bebeley (2016), understand about contraindications of muscle weakness due central fatigue, peripheral fatigue and lactic acid, Bebeley (2016), understand health education literacy level of stress due cognitive, emotional and physical factors Bebeley (2016), understand physical education literacy level due developmental, humanistic and fitness factors, Bebeley et al. (2017) and understand physical literacy level due locomotor-\&-body, sending and receiving skills, Bebeley et al. (2017), thereby not only increase advantages (pros.), motive, behavioural regulation, self-efficacy and weekly leisure time spent on physical activity for better physical activity status, but also could help individuals, communities, the environment and the public to control and reduce lifestyle-related sicknesses, mortality and morbidity, Bebeley et al. (2017); Tucker et al. (2017). Motivationin physical activity, could be expressed as the science of psychology that deals with the internal approach (intrinsic motivation) and the external approach (extrinsic motivation) that possesses both the factors of nature i.e. inborn tendencies (tendencies acquired by an individual before birth - innate abilities) and nurture i.e. environmental tendencies (tendencies acquired by an individual after birth in an environment), Bebeley et al. (2017), that could have the ability,power, focus, intellect and potential to initiates, ignites, guides, maintains goal-oriented physical activity, physical fitness, physical education, wellness and explain behaviours that could involve the holistic forces (i.e. emotional, social and cognitive forces) that activate the behavioural direction of an individual desires, needs and actions, which in includes the psychomotor learning (physique i.e. physical activity, fitness and exercise), affective learning (moral i.e. abstinence and adherence) and cognitive learning (intelligence quotient i.e. knowledge acquisition), Bebeley et al. (2017); Tucker et al. (2017).

This study only aimed at scoring the measured and evaluated factors under motor skill level of children and adolescents motivation in physical activity: a major concern for public health and physical education in maintaining motor skill development, healthy lifestyle, wellness, fitness and reduction in cardiovascular related illnesses, mortality and morbidity amongst children and adolescents, cased at University and Taiama Secondary Schools (USS and TSS) in Sierra Leone.

\section{Methodology}

\section{Respondents}

The survey sampled participants of one hundred and twentytwo $(\mathbf{N}=\mathbf{1 2 2})$ with $\mathbf{1 0 0 \%}$ response rate, selected mainly amongst Junior Secondary School (JSS)pupils through a process of simple random sampling (SRS) technique with a mean and standard deviation $(\mathbf{M} \pm \mathbf{S D})$ age of $(\mathbf{1 4 . 5} \pm \mathbf{5 . 5})$ ranged from nine to twenty(9-20)years.

\section{Instrumentation}

The following were the instruments adopted for the survey: mat and stopwatch for timing during Bent-Knee-Sit-Ups-

\section{Volume 6 Issue 12, December 2017}




\section{International Journal of Science and Research (IJSR) \\ ISSN (Online): 2319-7064}

Index Copernicus Value (2016): 79.57 | Impact Factor (2015): 6.391

Test, AAHPER (1976); floor space for acceptable traction, stop watch, two wooden blocks measured (2"x2"x4") for Shuttle-Run-Test, AAHPER(1976); measuring tape, masking tape, foam/sand and rectangular board for Standing-Long-Jump-Test, AAHPER (1976)and stopwatch with split timer for50-Yards-Dash-Test, AAHPER (1976).

\section{Procedure}

Each participant was tested and scored on their respective school campuses alongside the instructions provided for by the survey instrument, using smart phones, tablets and computers installed with census survey entry and processing (CSEntry. and CSPro.) applications software.

\section{Analysis}

Frequency Test with Descriptive Statistics, Test of Analysis of Variance (ANOVA) and Independent Samples Test from IBM SPSSv.23 Statistics were used to compute, analyze and compare the result findings of the survey using a significant value of $\boldsymbol{P}<0.05$.

\section{Results}

In this survey, it was evidenced that there were differences in the mean and standard deviation interpretations of motor skill test by age group, slated accordingly by highest scores as follows: Bend-Knee-Sit-Ups(15-17) years scored (2.72 \pm 0.861$)$, Shuttle-Run(09-11) years scored (3.00 $\pm \leq 0.000)$, Standing-Long-Jump (18-20) years scored $(2.75 \pm 0.809)$ and Fifty-Yards-Dash(09-11) years scored (4.00 $\pm \leq 0.000)$ for both USS and TSS combined, as referenced in table 1 .

Table 1: One Way Descriptive Statistics Analysis (DSA) by Age Group ( $\mathrm{N}=122)$

\begin{tabular}{|c|c|c|c|c|c|c|}
\hline \multirow{3}{*}{$\begin{array}{c}\text { Motor Skill } \\
\text { Test }\end{array}$} & \multicolumn{6}{|c|}{ Descriptive Statistics Frequency } \\
\hline & \multirow{2}{*}{\begin{tabular}{|c|} 
Age \\
Group
\end{tabular}} & \multirow[b]{2}{*}{$n$} & \multirow{2}{*}{ Mean } & \multirow{2}{*}{$\begin{array}{c}\text { Standard } \\
\text { Deviation }\end{array}$} & \multicolumn{2}{|c|}{ 95\%-CI-Mean } \\
\hline & & & & & Lower & Upper \\
\hline \multirow{4}{*}{$\begin{array}{c}\text { Bend-Knee- } \\
\text { Sit-Ups }\end{array}$} & $09-11$ & 01 & 1.00 & $\leq 0.000$ & 0.00 & 0.00 \\
\hline & $12-14$ & 24 & 2.38 & 0.875 & 2.01 & 2.74 \\
\hline & $15-17$ & 57 & 2.72 & 0.861 & 2.49 & 2.95 \\
\hline & $18-20$ & 40 & 2.50 & 1.109 & 2.15 & 2.85 \\
\hline \multirow[t]{4}{*}{ Shuttle-Run } & $09-11$ & 01 & 3.00 & $\leq 0.000$ & 0.00 & 0.00 \\
\hline & $12-14$ & 24 & 2.58 & 0.717 & 2.28 & 2.89 \\
\hline & $15-17$ & 57 & 2.53 & 0.570 & 2.38 & 2.68 \\
\hline & $18-20$ & 40 & 2.68 & 0.829 & 2.41 & 2.94 \\
\hline \multirow{4}{*}{$\begin{array}{l}\text { Standing- } \\
\text { Long-Jump }\end{array}$} & 09-11 & 01 & 1.00 & $\leq 0.000$ & 0.00 & 0.00 \\
\hline & $12-14$ & 24 & 2.21 & 0.779 & 1.88 & 2.54 \\
\hline & $15-17$ & 57 & 2.67 & 0.636 & 2.50 & 2.84 \\
\hline & $18-20$ & 40 & 2.75 & 0.809 & 2.49 & 3.01 \\
\hline \multirow{4}{*}{$\begin{array}{c}\text { Fifty-Yards- } \\
\text { Dash }\end{array}$} & $09-11$ & 01 & 4.00 & $\leq 0.000$ & 0.00 & 0.00 \\
\hline & $12-14$ & 24 & 2.54 & 0.721 & 2.24 & 2.85 \\
\hline & $15-17$ & 57 & 2.72 & 0.750 & 2.52 & 2.92 \\
\hline & $18-20$ & 40 & 2.88 & 0.853 & 2.60 & 3.15 \\
\hline \multicolumn{7}{|c|}{ Note: $\boldsymbol{C I}=$ Confidence Interval } \\
\hline
\end{tabular}

A motor skill test results were recorded according to highest scores executed during the test process under schools and age group as follows: Bend-Knee-Sit-Ups scored 43 under "Fair" with (35.2\%) of $\mathrm{F}=1.778$ (Age) and $\mathrm{F}=11.821$ (Schools), Shuttle-Run scored 62 under "Good" with (50.8\%), of $\mathrm{F}=0.477$ (Age) and $\mathrm{F}=10.733$ (Schools), Standing-Long-Jump scored 53 under "Good" with (43.4\%) of $\mathrm{F}=4.675$ (Age) and $\mathrm{F}=14.248$ (Schools) and Fifty-Yards-
Dash scored 48with (39.3\%) of $\mathrm{F}=1.796$ (Age) and $\mathrm{F}=14.057$ (Schools)for both University and Taiama Secondary Schools(USS and TSS), as slated in tables 2, 3 and 4 respectively.

Table 2: Descriptive Frequency Between Schools when Combined $(\mathrm{N}=122)$

\begin{tabular}{|c|c|c|c|c|c|c|c|c|}
\hline \multirow{2}{*}{ Motor Skill Test } & \multicolumn{8}{|c|}{ Descriptive Statistics Frequency } \\
\cline { 2 - 9 } & Poor & $\%$ & Fair & $\%$ & Good & $\%$ & $\begin{array}{l}\text { Very } \\
\text { Good }\end{array}$ & $\%$ \\
\hline \multicolumn{10}{|c|}{ USS \& TSS Combined } \\
\hline Bend-Knee-Sit-Ups & 17 & 13.9 & 43 & 35.2 & 38 & 31.1 & 24 & 19.7 \\
\hline Shuttle-Run & 06 & 4.9 & 46 & 37.7 & 62 & 50.8 & 8 & 6.6 \\
\hline Standing-Long-Jump & 07 & 5.7 & 49 & 40.2 & 53 & 43.4 & 13 & 10.7 \\
\hline Fifty-Yards-Dash & 03 & 2.5 & 48 & 39.3 & 48 & 39.3 & 23 & 18.9 \\
\hline
\end{tabular}

Table 3: Analysis of Variance (ANOVA) Statistics by Age Grouped ( $\mathrm{N}=122)$

\begin{tabular}{|l|c|c|c|c|c|}
\hline \multirow{2}{*}{ Motor Skill Test } & \multicolumn{5}{|c|}{ Analysis of Variance (ANOVA) } \\
\cline { 2 - 6 } & $\begin{array}{c}\text { Sum of } \\
\text { Squares }\end{array}$ & $d f$ & $\begin{array}{c}\text { Mean } \\
\text { Square }\end{array}$ & $F$ & Sig. \\
\hline USS \& TSS Combined \\
\hline Bend-Knee-Sit-Ups & 4.842 & 3 & 1.614 & 1.778 & 0.155 \\
\hline Shuttle-Run & 0.689 & 3 & 0.230 & 0.477 & 0.699 \\
\hline Standing-Long-Jump & 7.383 & 3 & 2.461 & 4.675 & 0.004 \\
\hline Fifty-Yards-Dash & 3.281 & 3 & 1.094 & 1.796 & 0.152 \\
\hline
\end{tabular}

Table 4: Analysis of Variance (ANOVA) Statistics by Schools Combined $(\mathrm{N}=122)$

\begin{tabular}{|c|c|c|c|c|c|}
\hline \multirow{2}{*}{ Motor Skill Test } & \multicolumn{5}{|c|}{ Analysis of Variance (ANOVA) } \\
\cline { 2 - 7 } & $\begin{array}{c}\text { Sum of } \\
\text { Squares }\end{array}$ & $d f$ & $\begin{array}{c}\text { Mean } \\
\text { Square }\end{array}$ & $F$ & Sig. \\
\hline \multicolumn{7}{|c|}{ USS \& TSS Combined } \\
\hline Bend-Knee-Sit-Ups & 10.041 & 1 & 10.041 & 11.821 & 0.001 \\
\hline Shuttle-Run & 04.721 & 1 & 04.721 & 10.733 & 0.001 \\
\hline Standing-Long-Jump & 07.377 & 1 & 07.377 & 14.248 & $\leq 0.000$ \\
\hline Fifty-Yards-Dash & 07.877 & 1 & 07.877 & 14.057 & $\leq 0.000$ \\
\hline
\end{tabular}

One-way Descriptive Statistics and T-Test Analysis (t) scores were recorded as follows: Bend-Knee-Sit-Ups scored $(2.85 \pm 0.963)$ boys and $(2.28 \pm 0.878)$ girls with t-value $(28.883)$ of sig. $(\leq 0.000)$, Shuttle-Run scored $(2.79 \pm 0.733)$ boys and (2.39 \pm 0.585$)$ girls with t-value (40.698) of sig. $(\leq 0.000)$, Standing-Long-Jump scored $(2.84 \pm 0.778)$ boys and $(2.34 \pm 0.655)$ girls with t-value $(37.018)$ of sig. $(\leq 0.000)$ and Fifty-Yards-Dash scored $(3.00 \pm 0.775)$ boys and $(2.49 \pm 0.722)$ girls with t-value $(37.791)$ of sig. $(\leq 0.000)$, as slated in tables 5 and 6.

Table 5: One-way Descriptive Statistics Analysis (DSA) Between Sexuality ( $\mathrm{N}=122)$

\begin{tabular}{|c|c|c|c|c|c|c|}
\hline \multirow{3}{*}{ Motor Skill Test } & \multicolumn{6}{|c|}{ One-way Descriptive Statistics Analysis } \\
\hline & \multirow{2}{*}{ Sex } & \multirow{2}{*}{$n$} & \multirow{2}{*}{ Mean } & \multirow{2}{*}{$\begin{array}{l}\text { Standard } \\
\text { Deviation }\end{array}$} & \multicolumn{2}{|c|}{ 95\%-CI-Mean } \\
\hline & & & & & Lower & Upper \\
\hline \multirow{2}{*}{$\begin{array}{c}\text { Bend-Knee-Sit- } \\
\text { Ups }\end{array}$} & Boy & 61 & 2.85 & 0.963 & 2.61 & 3.10 \\
\hline & Girl & 61 & 2.28 & & 5 & 2.50 \\
\hline \multirow[t]{2}{*}{ Shuttle-Run } & Boy & 61 & 2.79 & 0.733 & 2.60 & 2.97 \\
\hline & Girl & 61 & 2.39 & 0.585 & 2.24 & 2.54 \\
\hline \multirow{2}{*}{$\begin{array}{l}\text { Standing-Long- } \\
\text { Jump }\end{array}$} & Boy & 61 & 2.84 & 0.778 & 2.64 & 3.04 \\
\hline & Girl & 61 & 2.34 & 0.655 & 2.18 & 2.51 \\
\hline \multirow[t]{2}{*}{ Fifty-Yards-Dash } & Boy & 61 & 3.00 & 0.775 & 2.80 & 3.20 \\
\hline & Girl & 61 & 2.49 & 0.722 & 2.31 & 2.68 \\
\hline
\end{tabular}

\section{Volume 6 Issue 12, December 2017 www.ijsr.net}




\section{International Journal of Science and Research (IJSR) \\ ISSN (Online): 2319-7064}

Index Copernicus Value (2016): 79.57 | Impact Factor (2015): 6.391

Table 6: T-Test Analysis of One-Sample Test Between Schools when Combined ( $\mathrm{N}=122)$

\begin{tabular}{|c|c|c|c|c|c|c|}
\hline \multirow{3}{*}{ Motor Skill Test } & \multicolumn{6}{|c|}{ One Sample T-Test Analysis } \\
\hline & \multirow{2}{*}{ t-value } & \multirow{2}{*}{$d f$} & \multirow{2}{*}{$\begin{array}{l}\text { Sig.(2- } \\
\text { tailed) }\end{array}$} & \multirow{2}{*}{$\begin{array}{c}\text { Mean } \\
\text { Difference }\end{array}$} & \multicolumn{2}{|c|}{ 95\%-CI-Mean } \\
\hline & & & & & Lower & Upper \\
\hline \multicolumn{7}{|c|}{ USS \& TSS Combined } \\
\hline $\begin{array}{l}\text { Bend-Knee-Sit- } \\
\text { Ups }\end{array}$ & 28.883 & 121 & $\leq 0.000$ & 2.516 & 2.34 & 2.69 \\
\hline Shuttle-Run & 40.698 & 121 & $\leq 0.000$ & 2.54 & 2.42 & 2.66 \\
\hline $\begin{array}{l}\text { Standing-Long- } \\
\text { Jump }\end{array}$ & 37.018 & 121 & 00 & 2.54 & 2.4 & 2.68 \\
\hline Fifty-Yards-Dash & 37.791 & 121 & $\leq 0.000$ & 2.696 & 2.55 & 2.84 \\
\hline
\end{tabular}

\section{Discussion of Results}

The four measured, evaluated and scored variables in motor skill development level are all components of physical fitness (i.e. speed, agility, reaction time and power), Tucker et al. (2017); Bebeley et al. (2011), which explains about physical education programme on motor fitness of school pupils in Sierra Leone alongside speed, agility, reaction time and power.

The level of speed of the participants, which was tested using Fifty-Yards-Dash was positively skewed, which as a component of physical fitness and physical activity, is required for excellence performance in almost all sporting activities or competitions (athletics, swimming, games and sports etc.), fitness mobilization, physical activity improvement and motor skill development by every sport woman or man, Tucker et al. (2017); Bebeley et al. (2011). Agility, which was also tested using Standing-Long-Jump, indicates improved performance among participants with a positively skewed result that is also an important component of physical activity, fitness and wellness in many sporting events, which is the maneuverability of the body in action for accuracy and it is fundamental to good performance in all sports, which children and adolescents need to function effectively, Tucker et al. (2017); Bebeley et al. (2011).

Reaction Time was tested using Shuttle-Run, which shows an average level of improved performance. It is a physical fitness component skill related and is one of the requirements to win in sport and is as vital as other components like endurance and speed oriented events, showing an indication that children with good reaction time have tendency to excel in speed oriented sports, Tucker et al. (2017); Bebeley et al. (2011).

Power, which was tested using Bend-Knee-Sit-Ups, is another elemental component of physical fitness, which had little improved performance by participants. However, an early development of motor fitness for children, adolescents and youths is very essential for motivating them into doing sport and exercises that can either be recreational or competitive, which can be done through physical health education programmes, Tucker, et al. (2017); Bebeley et al. (2011).

\section{Conclusion and Recommendation}

In the final analysis, it was noted that, majority of the pupils both boys and girls within the age range of 15-20 recorded high values especially the boys with respect to their frequency and mean responses during the test, displaying an evidence of physical activity, exercise and motor skill development amongst the pupils, which was very helpful to the researchers during the test process, though the technicalities and names of the activities were faced with a little bit of challenges. Also evident was that, the respondents of the schools targeted were very much impressed about the activities (i.e. physical activity of motor skill fitness level).However, concerns were raised by their counterparts who were not selected due to the simple randomly sampled (SRS) respondents for not being part of the motor skill development testing exercise.

As stipulated in the discussion and conclusion, this study recommends that, stakeholders in the educational sector should be proactive in educating and encouraging pupils with regards the relevance of healthy lifestyle through physical activity and health education in society. Also, that parents should be role models and encourage their children to take part in physical activities and health education activities, which will lead to a healthy lifestyle and a major decrease in obesity, cardiovascular related illnesses, morbidity and mortality amongst children and adolescents.

\section{Acknowledgement}

The authors express thanks and appreciation to all staff and pupils of the two selected secondary schools, whose immense co-operation rendered this study to fruition.

\section{Conflict of Interests}

The authors declared no conflict of interests regarding the publication of this manuscript.

\section{References}

[1] Bebeley, S. J. (2016). Adolescents' Health Literacy Level of Asthma Due Environmental, Physical and Medical Conditions; PARIPEX-Indian Journal of Research: 5(6) 7-9.

[2] Bebeley, S. J. (2016). Adolescents' Health Literacy Level of Muscle Atrophy Due Physical, Medical and Exercise Factors; PARIPEX-Indian Journal of Research 5(5) 7-9

[3] Bebeley, S. J. (2016). Adolescents' Health Education Literacy Level of Stress Due Cognitive, Emotional and Physical Factors; PARIPEX-Indian Journal of Research: 5(7) 19-21.

[4] Bebeley, S. J. (2016). Adolescents' Knowledge about the Contraindications of Muscle Weakness Due Central Fatigue, Peripheral Fatigue and Lactic Acid as Health Education Strategy in Lifestyle Management; PARIPEX-Indian Journal of Research 5(4) 2-4

[5] Bebeley, S. J. (2015). An Investigation into the Measurement Level of Maximum Volume of Oxygen Consumption Using Cooper 12-Minutes Run-Test; Journal of Exercise Science and Physiotherapy: 11(2)65-75.

[6] Bebeley, S. J. and Laggao, S. A. (2011). Effects of SixMonth Physical Education Programme on Motor Fitness 


\section{International Journal of Science and Research (IJSR) \\ ISSN (Online): 2319-7064}

Index Copernicus Value (2016): 79.57 | Impact Factor (2015): 6.391

of Primary School Pupils in Sierra Leone; Journal of Nigeria Association for Physical, Health Education, Recreation, Sport and Dance:2(1) 100-106.

[7] Bebeley, S. J., Laggao, S. A. and Tucker, H. J. (2017). Adolescents' Physical Education Literacy Level Due Developmental, Humanistic and Fitness Factors; IOSR Journal of Sports and Physical Education (IOSRJSPE): 4(2) 15-18.

[8] Bebeley, S. J., Laggao, S. A. and Tucker, H. J. (2017). Athletes Abstinence Knowledge from Eating Disorders as Health Education Method in Decreasing Unhealthy Ageing with Reference to Physical and Mental Health; Journal of Exercise Science and Physiotherapy: 13(1) 8-22.

[9] Bebeley, S. J., Laggao, S. A. and Tucker, H. J. (2017). Knowledge of University Athletes about Knowing and Monitoring of Vital Signs as Preventive Strategy in Reducing Early and Unsuccessful Ageing; Journal of Exercise Science and Physiotherapy: 13(1) 31-52.

[10] Bebeley, S. J., Liu, Y. and Wu, Y. (2017). Decisional Balance Scale For College Students' Level Of Motivation In Physical Activity;Global Journal for Research Analysis: 6(7) 453-455.

[11] Bebeley, S. J., Liu, Y. and Wu, Y. (2017). Physical Exercise Self-Efficacy For College Students' Level Of Motivation In Physical Activity; International Journal of Science and Research: 6(8) 81-85.

[12] Bebeley, S. J., Liu, Y. and Wu, Y. (2017). Weekly Leisure Time Exercisefor College Students' Level of Motivation in Physical Activity: A Concern for Physical and Public Health Education;International Journal of Scientific Research: 6(9) 651-654.

[13] Bebeley, S. J., Wu, Y. and Liu, Y. (2016). Athletes' Knowledge about Preventing Sports Injuries as Prime Prevention Strategies in Slowing Ageing Process; Journal of Exercise Science and Physiotherapy: 12(1) 25-37.

[14] Bebeley, S. J., Wu, Y. and Liu, Y. (2016). Athletes' Knowledge about the Non-Usage of Drugs as Prime Prevention Strategies in Slowing Ageing Process; Journal of Exercise Science and Physiotherapy: 12(1) 57-68.

[15] Bebeley, S. J., Wu, Y. and Liu, Y. (2017). Behavioural Regulation In Exercise For College Students' Level Of Motivation In Physical Activity;International Journal of Scientific Research: 6(6) 580-583.

[16] Bebeley, S. J., Wu, Y. and Liu, Y. (2016). Knowledge of Njala Campus Athletes about Abstinence from Diseases Associated with Unsafe Sexual Practices aimed as Primary Prevention Strategy in Minimizing the Process of Ageing; Journal of Exercise Science and Physiotherapy 12(1) 42-56.

[17] Bebeley, S. J., Wu, Y. and Liu, Y. (2017). Motives for Physical Activity for College Students' Level of Motivation in Physical Activity; International Journal of Science and Research: 6(5) 2377-2382.

[18] Bebeley, S. J., Wu, Y. and Liu, Y. (2017). Motivational Level of College Students' in Physical Activity: A Concern for Public Health Education;International Journal ofScience and Research: 6(10) 816-821.

[19] Hunsicker, P. A. and Reif, G. G. (1976). AAPHER Youth Fitness Test Manual Revised Edition. AmericanAlliance for Health,Physical Education and

\section{Recreation, Washington,
http://files.eric.ed.gov/fulltext/ED120168.pdf}

D.C.

[20] Laggao, S. A., Bebeley, S. J. and Tucker, H. J. (2017). Adolescents' Physical Literacy Level Due Locomotor\&-Body, Sending and Receiving Skills; PARIPEXIndian Journal of Research: 6(1) 255-257.

[21] Tucker, H. J.,Bebeley, S. J. and. Laggao, S. A., (2017).Children and Adolescents' Fitness Skill Level in Physical Activity: A Motivational Concern for Public Health Education; International Journal ofScience and Research: 6(11) 18-22.

Volume 6 Issue 12, December 2017 